\title{
Assessment of the synergic effect of Avastin and VEGF siRNA on inhibition of cell proliferation and angiogenic factor expression of human breast cancer cells
}

\section{Abdolkhalegh Deezagi ( $\sim$ deezagi@nigeb.ac.ir)}

National Institute for Genetic Engineering and Biotechnology https://orcid.org/0000-0001-5748-2336

Bahar Ghorbani

NIGEB: National Institute for Genetic Engineering and Biotechnology

\section{Research Article}

Keywords: Breast cancer, Avastin, siRNA, MCF-7, Vascular endothelial growth factor

Posted Date: September 17th, 2021

DOI: https://doi.org/10.21203/rs.3.rs-889004/v1

License: (c) (1) This work is licensed under a Creative Commons Attribution 4.0 International License. Read Full License 


\section{Abstract}

Angiogenesis is an important process in tumor growth and metastasis and vascular endothelial growth factor (VEGF) plays an important role in this process. Several VEGF inhibitors have been developed as anticancer agents including humanized monoclonal antibodies, and various small molecules. The aim of this work was to investigate the effect of combination of VEGF siRNA and Avastin on breast cancer MCF7 cell line behavior. For this purpose, the cells were treated with different concentrations of Avastin and/or VEGF siRNA and their combination. The cell survival and cell proliferation were assayed by cell counting, trypan blue and MTT tests. The cell migration was assayed by scratching test. VEGF expression was assayed by RT and real-time PCR and ELISA methods. Results indicated the significant increase in cell death following treatment with Avastin (50\% cell death at $100 \mu \mathrm{g} / \mathrm{ml})$. Cell death with VEGF siRNA transfection was lower than Avastin, however, it was significant. This result in VEGF siRNA + Avastin (100 $\mu \mathrm{g} / \mathrm{ml}$ ) treatment was greater compared to treatment with each of these compounds alone (47\%). Scratching results also showed the synergic effect of VEGF siRNA and Avastin ( $57 \%$ decrease). Real-time PCR results showed that Avastin at concentrations of $\geq 50 \mu \mathrm{g} / \mathrm{ml}$ led to 2.5 to 7.5 -fold decrease in VEGF expression levels. Also, treatment with VEGF siRNA led to 15.5-fold decrease in VEGF expression. Finally, VEGF expression following VEGF siRNA + Avastin treatment led to a significant 47.5-fold decrease in VEGF expression. It could be concluded that combination of VEGF siRNA and Avastin have a more significant impact on the inhibition of cell growth and migration and it can probably be used as an effective therapeutic approach.

\section{Highlights:}

- Avastin (up to $100 \mu \mathrm{g} / \mathrm{ml}$ ) reduced cell growth of MCF-7 cells up to $25 \%$ in comparison to untreated control in a dose dependent manner

- VEGF siRNA have reduced cell proliferation about 37\%.

- Combination of $25 \mu \mathrm{g} / \mathrm{ml}$ of Avastin by VEGF siRNA inhibit the cell growth in a synergism manner about $57 \%$.

- Real-time PCR results showed that Avastin at concentrations of $\geq 50 \mu \mathrm{g} / \mathrm{ml}$ led to 2.5 to 7.5 -fold, VEGF siRNA led to 15.5 -fold and combination of them led to a significant 47.5 -fold decrease in VEGF expression.

- -Cell migration was inhibited about 15, 40 and $60 \%$ in presence of $25 \mu \mathrm{g} / \mathrm{ml}$ of Avastin., VEGF siRNA and their combination respectively.

\section{Introduction:}

Human breast cancer is one of the most important health problems among women which treated by radiotherapy, chemotherapy and biotherapy $[1,2]$. One of the most reliable strategies for inhibition of tumor cell growth, proliferation and arrest of cell cycle is blocking of new vessels formation and angiogenesis by blocking angiogenesis [3]. Stimulation of angiogenesis is triggered by various 
angiogenic factors such as integrin cell adhesion molecules, prostaglandins, Vascular Endothelial Growth Factor (VEGF) and Fibroblast Growth Factor (FGF) [4]. VEGF regulates several cell functions including; proliferation, differentiation, permeability, vascular tone and the production of vaso-active molecules [5]. Cancerous cells and many cell lines produce and secret VEGF and its receptor FLK-1. VEGF expression and secretion by tumor cells and surrounding fibroblasts resulted in the formation of intercellular new micro vessels in breast cancer [6]. Therefore, targeting of VEGF is a strategic point in regulating angiogenesis in the tumor and may inhibit tumor vacuolization and growth as therapeutic manner [7-9]. Several VEGF inhibitors have been developed as anticancer agents including a humanized anti VEGF-A monoclonal antibody (Bevacizumab or Avastin), various small molecules inhibiting VEGFR2 signal transduction, a VEGF receptor chimeric protein and VEGF siRNA [7-9]. The literature reviews show that blocking angiogenesis by some small chemical inhibitors might have very limited effect on cancerous cells growth [10-12]. Experiments whit neutralizing antibodies and other inhibitors demonstrated that blockade of the VEGF pathway is not completely sufficient to suppress angiogenesis associated with breast cancer tumors growth and show some side effects [13.14]. The use of neutralizing antibodies such as Avastin have some limitation from the cost, economic aspect, side effects and so on. For overcoming to these limitation, combination of Avastin by other agents for synergism is an attractive subject in the field of cancer research in recent years.

A growing number of studies have suggested that RNA interference (RNAi) as a promising gene manipulation technique with therapeutic potential, when used alone or in conjunction with other treatments $[15,16]$. However, siRNA or shRNA-based therapy relies on successful delivery to the target and in addition, siRNA has been widely explored for use in combination therapy $[17,18]$. The use of siRNA in combination with other anti-cancer therapeutics has been shown to improve outcomes by either increasing the sensitivity of breast cancer towards a therapeutic modality, or by working in an additive or synergistic fashion $[19,20]$.

The use of siRNA technology for cancer treatment have some challenges and opportunities too. These challenges and opportunities have discussed by Wang et.al in detail [21]. For overcoming to these challenges, combination of siRNA by other agents for synergism is an attractive subject in the field of cancer research in recent years. Today, interest to finding anti-angiogenesis combined drugs for anticancer therapy and understanding the molecular mechanism of their biological actions has peaked.

Interest to finding anti-angiogenesis agents and combination of them by Avastin for anticancer therapy is attractive. Understanding the molecular mechanism and their biological actions are necessary too. Because of some limitation and disadvantage of each agent, novell combination approaches to inhibit these processes by probably synergistic effect are under investigation.

The aim of this study was to evaluate the potency and synergism of specific VEGF short-interfering RNA (siRNA) to suppress human VEGF expression in combination by Avastin on the human breast cancer MCF-7 cells growth, proliferation, migration, VEGF expression and secretion. 


\section{Material And Methods:}

\section{Cell culture and treatments by Avastan:}

Human breast cancer cell line (MCF-7) was provided from American Type Culture Collection (ATCC, Rockville, MD, USA) and were cultured in DMEM medium (Gibson, Paisley, U.K.) supplemented with 10\% fetal bovine serum (FBS, Invitrogen) and $100 \mathrm{U} / 100 \mu \mathrm{g} / \mathrm{ml}$ penicillin-streptomycin (Gibco, Paisley, U.K.). The cells were trypsinized and sub cultured twice a week. In logarithmic phase of growth, $2.0 \times 10^{4}$ the cells were seeded in every wells of 6 well plates $\left(250 \times 10^{3}\right.$ cells/well) and/or $2.0 \times 10^{4}$ cells/well in 96 flat bottom micro wells (Nunc, Denmark). The cells were incubated over night for complete adherence. Then the cells were treated by $12.5-500 \mu \mathrm{g} / \mathrm{ml}$ of Avastin (Bevacizumab) (Roche, Hafteman-La, Basel, Switzerland). The cells were incubated in DMED medium, supplemented by $10 \%$ of FBS for $96 \mathrm{hr}$ at $37^{\circ} \mathrm{C}$, $5 \%$ of $\mathrm{CO}_{2}$. After $96 \mathrm{hr}$, the cells pellet and supernatants were separately collected and the total cell number, viability, MTT cell proliferation assays, VEGF expression and secretion were done as below.

\section{siRNAs transfection}

The MCF-7 cells were cultured for 24 hours and transfected by 3double-stranded RNA and oligo targeting VEGF which were purchased from Santa Cruz (Santa Cruz Biotechnology Inc, Bergheimer, Heidelberg, Germany). Oligoes which used as scramble and VEGF siRNA have sequences as:

Scramble siRNA sense: 5' -GCG GAG AGG CUU AGG UGU A[TT]-3'.

Antisense: 5'-UAC ACC UAA GCC UCU CCG C[TT]-3'.

hVEGF-siRNA, sense strand RNA, 5'-GGA GUA CCC UGA UGA GAU C[TT]-3'.

hVEGF antisense strand RNA, 5'-GAU CUC AUC AGG GUA CUC C[TT]-3'.

The cells (with $60 \%$ of confluency) were incubated in $800 \mu \mathrm{L}$ of antibiotic and serum free DMEM in sixwell plate per well. $10 \mu \mathrm{L}$ of 3 siRNAs stock $(10 \mu \mathrm{mol})$ and $10 \mu \mathrm{L}$ of an X-termGENE (Roche) transfection reagent were diluted to $100 \mu \mathrm{L}$ antibiotic and serum free DMEM and then incubated separately at room temperature for $5 \mathrm{~min}$. The two mixtures were combined and incubated at room temperature for $30 \mathrm{~min}$. The siRNAs, X-term mixtures were added drop wise to cells in well. The cells were incubated for 6 hours. Then $1000 \mu \mathrm{L}$ of $20 \%$ FBS DMEM were added to cells, after 72 hours' cell detached and analyzed for cell proliferation, viability, qRT-PCR and ELISA assay as described below. To analyze the percent of transfection of cells, the experiment was performed by control siRNA conjugate with FITC (Invitrogen) and the percent of FITC positive cells were analyzed by flow cytometry according to the manufactures recommendations.

For combination study the cells were treated by $25 \mu \mathrm{g} / \mathrm{ml}$ of Avastin and VEGF siRNA.

\section{Cell proliferation and growth}


Cell number counting and viability (Trypan blue dye exclusion) were enumerated using a Neobar hemocytometer.

MTT assay: After $96 \mathrm{hr}$ of incubation, $10 \mu \mathrm{l}$ of freshly prepared (3-(4, 5-dimethylthiazol-2-yl)-2, 5diphenyltetrazolium bromide (MTT) (Sigma, St. Louis, MO, U.S.A.) solution ( $5 \mathrm{mg} / \mathrm{ml}$ in PBS) was added to each microwell and were incubated for $4 \mathrm{hr}$. Then, $50 \mu \mathrm{l}$ of MTT lysis solution (20\% Sodium Dodcyl Sulphate W/V and 50\% Dimethy Formamide V/V) was added to each well and incubated overnight. Absorbance was read at $580 \mathrm{~nm}$ using a Titretek multiscan ELISA reader (Labsystems Multiskan, Roden, Netherlands).

\section{Semi-quantitative detection of VEGF mRNAs by RT-PCR}

Avastin and/or VEGF siRNA treated cells were collected and total RNA was extracted by using the Tripur isolation reagent (Roche, Mannheim, Germany), according to the manufacture's protocol. RNA yield and purity were quantitated by measuring optical density $\left(\mathrm{OD}_{260 / 280}\right)$ using a Nanodrop (Beckman Coulter Inc. CA, USA). First-strand cDNA was synthesized from $1 \mu \mathrm{g}$ of total RNA using Maurine Maloney Leukemia virus (M-MLV, Fermentas) and reverse transcriptase (Fermentas Gmbh, Leon-Rot, Germany) with oligo-dT primer (Fermentas Gmbh, Leon-Rot, Germany), according to the manufacturer's instructions. The VEGF and GAPDH cDNA were amplified by the following primers:

hVEGF forward: 5'-CCA TGA ACT TTC TGC TGT CTT-3', and reverse: 5'-ATC GCA TCA GGG GCA CAC AG3/; GAPDH forward: 5'-AAT CCC ATC ACC ATC TTC CA-3/' and reverse: 50/GTC ATC ATA TTT GGC AGG TT$3^{\prime}$.

The expected sizes of the RT-PCR product were $121 \mathrm{bp}$ for GAPDH and $250 \mathrm{bp}$ for VEGF. The thermal cycling conditions for amplification of those fragments were as follows: $94{ }^{\circ} \mathrm{C}$ for $10 \mathrm{~min}$., followed by 35 cycles at $94^{\circ} \mathrm{C}$ for $50 \mathrm{~s} ; 54^{\circ} \mathrm{C}$ for $30 \mathrm{~s} ; 72^{\circ} \mathrm{C}$ for 60 s. This was followed by re-extension at $72{ }^{\circ} \mathrm{C}$ for 10 min. The PCR products were separated on a $2 \%$ agarose gel (using $0.5 \times$ TBE buffer) and visualized by ethidium bromide staining. For quantitation each band of gel was scanned by image analysis program (ImageJ. Exe). The expression of the target genes was quantified and then normalized by an endogenous reference housekeeping gene (GAPDH) relative to the calibrator (untreated cells). Relative intensity of each gene mRNA and fold of change referred to untreated control cells.

\section{Real-Time PCR quantitative detection of the VEGF mRNAs:}

Quantitative real-time PCR was carried out on cDNAs prepared for conventional RT-PCR. We used the ABI PRISMTM 7700 Sequence Detector System (PE Applied Biosystems) and the fluorescent dye SYBR ${ }^{\circledR}$ Green and the amount of PCR products was determined based on the fluorescence produced during the extension step of each cycle in a closed tube. To normalize the amount of total RNA present in each reaction, we used GAPDH as housekeeping gene an internal control. The threshold cycle (Ct) value for each sample was proportional to the log of the initial amount of input cDNA. Relative expression levels of VEGF in each treatment group were derived from normalizing the Ct value of genes against that of an 
endogenous reference and a calibrator, where by GAPDH was used as a normalizer against untreated cells as a calibrator. Quantitative data were analyzed and relative quantification of VEGF mRNAs were derived by the $2^{-\Delta \Delta C} T$ methods.

\section{Quantitative ELIZA for VEGF}

The amount of secreted VEGF in response to Avastin and/or VEGF siRNA by cells were measured in supernatants by using commercial Calbiochem human VEGF ELISA kits. (Calbiochem-Merck-Bioscience, Darmstadt, Germany) according to the procedure manual of the kits. The method is a "sandwich" enzyme immunoassay employing monoclonal and polyclonal antibodies. Quantitation is achieved by construction of a standard curve using known concentrations of VEGF calibrators of the kit.

\section{Scratching assay}

Cell migration and quantification was done using the wound healing assay as described by Bobadilla and co workers [22]. Briefly, equal numbers of cells $\left(5 \times 10^{5}\right)$ were plated and kept overnight in 6-well plates. After that the monolayer of cells was carefully wounded by manual scratching with a micro-pipette tip head. Exactly, the cells were treated with different concentration of Rosuvastatin and/or Avastin. Treated cells were cultured in complete growth medium and incubated for $96 \mathrm{hr}$. The wounded regions were photographed at different times interval (0-96hr) using a phase contrast microscope (Nikon). The photographs of the cells were analyzed using a Cell science software program. The distance between the two sides of scratch layers of images taken from migration of all concentrations at specified times was determined by the Cell science software.

\section{Statistical analysis}

Each experiment was minimally performed three times for all data, each carried out in duplicated sequences. Data were analyzed using a One-Way Analysis of variance (ANOVA) Values were given as the mean \pm Standard Deviation (SD) and analytical variables were compared by using the students' t-Test. By convention, a a-level of $p<0.05$ was considered to be statistically significant

\section{Results:}

\section{Cell proliferation}

Initially, the morphology and behavior of cells which treated with different concentrations of Avastin and/or VEGF siRNA and/ or combination of them were observed under an invert microscope after $72 \mathrm{hrs}$. (Figs. 1) Avastin and VEGF siRNA treatment did not affect MCF-7 cells morphology and behavior. Increasing of Avastin concentration slightly decreased the cell density, confluency and adherence (Fig. 1bd) $>$ In presence of VEGF siRNA the cell density and confluence decreased moderately (Fig. 1E). In combination of Avastin and VEGF siRNA the cells density and confluency were strongly decreased in comparison to untreated cells (Fig. 1F) 
These cells were trypsinized and collected after $72 \mathrm{hr}$. The cells' viability and growth were assayed by using trypan blue, neobar cell counting and MTT assays. The result of cell counting was shown in Fig. 2 . Avastin inhibited cell growth potential and cell proliferation parameters from $20-50 \%$ in the presence of Avastin $(25-100 \mu \mathrm{g} / \mathrm{ml})$ incubation in comparison of untreated control cells after $48-72 \mathrm{hr}(\mathrm{p}<0.05)$ (Fig. 2a and b). The results indicate that, VEGF siRNA inhibit cell proliferation of MCF-7 cells about 15$20 \%$ in comparison to control cells after $48-72$ hr. (Fig. $2 \mathrm{c}$ and d). Combination of Avastin and VEGF siRNA decreased cell numbers in comparison by alone treatment (Fig. 2E). The results indicate that, combination of $100 \mu \mathrm{g} / \mathrm{ml}$ of Avastin by VEGF siRNA inhibited the cell growth and cell numbers about $60 \%$ in comparison to untreated cells and about $40 \%$ in comparison to alone treatments $(p<0.01)$ (Fig. 2E)

The cells viability curves of MCF-7 cells in response to Avastin and VEGF siRNA was shown in Fig. 3. Results indicated that in lower concentration of Avastin $(12.5 \mu \mathrm{g} / \mathrm{ml})$ the viable cells are more than $90 \%$ after $48 \mathrm{hr}$ (Fig. 3a) and after $72 \mathrm{hr}$ about $20 \%$ of the cells were died (Fig. 3b). The cells viability was decreased from $75-51 \%$ in presence of $25-100 \mu \mathrm{M}$ of Avastin for $48 \mathrm{hr}$ and $50-25 \%$ for $72 \mathrm{hr}$ incubation. Treatment of cells by VEGF siRNA have not significant cytotoxic effect on cell viability (Fig. 3c). Combination of $100 \mu \mathrm{g} / \mathrm{ml}$ of Avastin by VEGF siRNA resulted in about $15 \%$ lowering of viability after $48 \mathrm{hr}$ incubation in comparison by alone treatments $(p<0.05)$ (Fig. 3d)

In MTT assay, the absorbance values of 4 independent tests were averaged and growth curves were constructed (Fig. 4). The result indicated that, Avastin inhibited cell growth potential and cell proliferation parameters from $25-55 \%$ in the presence of Avastin $(25-500 \mu \mathrm{g} / \mathrm{ml})$ incubation in comparison of untreated control cells after 48hr ( $\mathrm{p}<0.05$ ) (Fig. 4a) and $40-70 \%$ after $72 \mathrm{hr} p<0.01$ ) Fig. 4b). The results indicate that, VEGF siRNA inhibit cell proliferation of MCF-7 cells about $20 \%$ in comparison to control cells after $48 \mathrm{hr}$ (Fig. 4c). Combination of Avastin and VEGF siRNA decreased MTT absorbance in comparison by alone treatment (Fig. 4c). The results indicate that, combination of $100 \mu \mathrm{g} / \mathrm{ml}$ of Avastin by VEGF siRNA inhibited the cell growth and cell proliferation about $25-30 \%$ in comparison to untreated cells and about $30-40 \%$ in comparison to alone treatments $(p<0.01)$ (Fig. 4c)

\section{Effect of VEGF siRNA and Avastin on the expression of VEGF:}

To examine the level of VEGF mRNA expression by MCF-7 cells in response to VEGF siRNA and Avastin; RT-PCR were performed. The treated cells were collected and total RNAs were extracted and the quality of the nucleic acids was measured by Nano-drop. After that, RT-PCR, and consequently Real-time PCR, were employed by the designed specific primers as described in materials and methods to analyze VEGF gene expression. The PCR products were separated on a $2 \%$ agarose gel and visualized by ethidium bromide staining (Fig. 5). The intensity of gels indicates that the expression of VEGF in response to Avastin was decreased in a dose dependent manner (Fig. 5a). VEGF siRNA inhibited the VEGF expression and combination treatment was sharply inhibited the expression. For quantitation each band of gel was scanned by image analysis program (ImageJ. Exe) and by Real time PCR too. Quantitative real-time PCR was carried out on cDNAs prepared for conventional RT-PCR. Relative intensity of each gene mRNA and 
fold of change referred to untreated control cells were shown in Fig. 5c, $d$ and e. The results presented in Fig. $5 c$ show that, treatment of MCF-7 cells by Avastin inhibited VEGF expression about 20 to $80 \%$ in presence of 12.5 to $500 \mu \mathrm{g} / \mathrm{ml}$ of Avastin in a linear dose dependent manner $(\mathrm{p}<0.05)$. VEGF expression was decreased from about $98 \%$ in presence of VEGF siRNA in comparison by untreated cells and scramble siRNA treated cells (Fig. $5 d)(p<0.01)$. In combination of $100 \mu \mathrm{g} / \mathrm{ml}$ of Avastin by VEGF siRNA the expression was shapely inhibited in comparison to untreated control cells and alone treatment (Fig. 5e) $(p<0.001)$.

VEGF content in supernatants were quantitavely measured by using VEGF ELISA test too. The VGEF content of samples were calculated from the standard curve of calibrators of the kit. Results show that in presence of Avastin (25-500 $\mathrm{mg} / \mathrm{ml})$ and VEGF siRNA and their combination the VEGF content was decreased from $>95 \%$ to complete inhibition in secretion respectively in comparison to untreated cells (Data was not shown).

\section{The effects of Avastin and VEGF siRNA on migration of MCF-7 cells in scratching method}

The effect of Avastin and/or VEGF siRNA on proliferation and migration of MCF-7 cells were done by scratching assay as described in the Materials and Methods. The wounded regions were photographed after $96 \mathrm{hr}$ by using a phase contrast microscope (Fig. 6A). The distance between the two sides of scratch layers of images taken from migration of all concentrations at specified times was determined by the Cell science software. The average migration distance in each photograph was calculated. The percentage difference for each concentration was calculated and compared to untreated control and alone treated cells. The calculated data were presented as a graph generated (Fig. 6B). The cell migration was inhibited about $20-40 \%$ in presence of $12.5-100 \mu \mathrm{g} / \mathrm{ml}$ of Avastin $(p<0.05)$ and about $45 \%$ in presence of VEGF siRNA $(p<0.01)$ in comparison to untreated cells. In combination of $100 \mu \mathrm{g} / \mathrm{ml}$ of Avastin by VEGF siRNA the migration was inhibited about $55 \%(p<0.01)$ in comparison to untreated cells and alone treatment $(p$ $<0.01)$.

\section{Discussion:}

Vascular Endothelial Growth Factors (VEGFs) and VEGF receptors mediate a plethora of biological processes in endothelial cells such as cell proliferation, migration, differentiation, regulation of vessel permeability and production of vasoactive molecules. In cancer, angiogenesis plays an important role in tumor growth and metastasis. VEGF is one of the important angiogenic cytokine which expresses by cancerous cells in tumors. Several VEGF inhibitors have been developed as anticancer agents including humanized monoclonal antibodies and various small molecules.

The use of siRNA in combination with other anti-cancer therapeutics has been shown to improve outcomes by either increasing the sensitivity of cancer towards a therapeutic modality, or by working in an additive or synergistic fashion. Several studies on the combined treatment of angiogenic inhibitors and chemotherapy such as avastin combined with paclitaxel and carboplatin in the treatment of nonsmall cell lung cancer [23], concomitant delivery of avastin with doxorubicin for the treatment of breast 
cancer [24] and the simultaneous treatment of VEGF siRNA and doxorubicin have focused on the treatment of liver carcinoma [25].

In general, new strategies are needed to increase the effectiveness of current chemotherapy drugs Therefore, in the present study, we aimed to investigate the synergistic effect of Avastin chemotherapy and VEGF siRNA gene therapy. Our results from the cell proliferation aspect showed high cytotoxic effect of avastin after 72 hours of treatment. For this reason, a 48-hour treatment with Avastin was considered the ideal treatment time for subsequent tests. A significant increase in cell death following treatment with avastin at concentrations of 50,100 and $500 \mu \mathrm{g} / \mathrm{ml}$. The rate of cell death in the treatment with VEGF siRNA also increased significantly, which was much lower than the treatment with different concentrations of avastin. However, this increase in cell death was greater in the simultaneous treatment of cells with VEGF siRNA and avastin at a concentration of $100 \mu \mathrm{g} / \mathrm{ml}$ than in the treatment with either of these compounds alone.

. These results indicate that this efficient system, ie the simultaneous use of VEGF siRNA and Avastin, can reduce the dose of the drug and consequently reduce the side effects of the drug, which is due to the economic cost of Avastin. It is also more economical. The results of trypan blue and methyl green staining also confirmed these results. Thus, the percentage of cell viability as well as the total number of cells decreased significantly after 72 hours of treatment with avastin, indicating the toxicity of this drug if the cells were exposed for a long time. Also, the percentage of survival and the total number of cells decreased in both VEGF siRNA treatments alone and avastin alone, and this decrease in VEGF siRNA transfected cells treated with avastin alone compared to the two groups alone. It was significantly more. As with the MTT results, these results demonstrate the synergistic effect of the combined use of VEGF siRNA and avastin on overcoming the drug resistance of cells.

VEGF has been shown to protect tumor cells by inducing the apoptotic genes. The Bcl-2/Bax family includes both anti-apoptotic and pro-apoptotic members that have different effects on mitochondria. Bax can increase the release of cytochrome $c$ from the cytosol into the cytochrome. This leads to inhibition of cytochrome $c$ release, which is involved in the induction of apoptotic effects. VEGF siRNA has been shown to reduce the expression of the anti-apoptotic protein Bcl-2 and has no effect on the Bax apoptotic protein in MCF-7 cells. Thus, it has been suggested that inhibition of VEGF by siRNA by disturbing the balance between members of the Bcl-2 family may lead to increased cellular apoptosis. The expression ratio of anti-apoptotic and pre-apoptotic proteins, such as Bcl-2 / Bax, is essential for the induction of apoptosis, and this ratio determines the cell's susceptibility to apoptosis. A change in the Bcl-2 / Bax ratio stimulates the release of cytochrome $c$ from the mitochondria to the cytosol. It has been shown that this ratio decreases significantly following treatment with VEGF siRNA in MCF-7 cells, and a decrease in this ratio may be the mechanism by which MCF-7 cell apoptosis is induced. In fact, VEGF siRNA has been shown to reduce VEGF expression, followed by a decrease in Bcl-2 / Bax ratio, cytochrome c release, and caspase-3 activation in the lower extremities, leading to cellular apoptosis [26]. 
Combination therapy relies on the simultaneous action of multiple therapeutic entities to exploit additive or synergistic effects and enhance therapeutic efficiency. Combination chemotherapy refers to the grouping of multiple chemotherapeutic agents that use different mechanisms to treat cancer. The combination strategy not only enhances therapeutic efficiency, but also reduces the risk of severe side effects caused by cytotoxicity of individual drugs $[27,28]$.

\section{Conclusion}

Considering the results of the current study, it could be stated that dual treatment with VEGF siRNA and Avastin have a more significant impact on the inhibition of cell growth and migration, and considering the high cost of Avastin and efficacy of siRNA in reducing the gene expression of VEGF, combination treatment of cells with lower effective concentrations, can be assessed as a more efficient approach in in vivo studies and in case these results are replicable, it can be used as an effective therapeutic approach.

\section{Declarations}

Acknowledgment: This work was supported by research funds (No. 540) from National Institute of Genetic Engineering and Biotechnology, Tehran- Iran.

Declaration of interest: The authors report no conflicts of interest. The authors alone are responsible for the content and writing of the paper.

Ethical approval: The study protocol was approved by the Research Ethics Committee at National institute of Genetic Engineering and Biotechnology (Tehran-Iran).

\section{References}

1. Tao Z, Shi A, Lu C, Song T, Zhang Z, Zhao J (2015) Breast cancer: epidemiology and etiology. Cell Biochem Biophys 72:333-338

2. Waks AG, Winer EP (2019) Breast cancer treatment: a review. Jama 321:288-300

3. Makrilia N, Lappa T, Xyla V, Nikolaidis I, Syrigos K (2009) The role of angiogenesis in solid tumours: an overview. European journal of internal medicine 20:663-671

4. Melincovici CS, Bosca AB, Susman S, Marginean M, Mihu C, Istrate M, Moldovan I-M, Roman AL, Mihu CM (2018) Vascular endothelial growth factor (VEGF)-key factor in normal and pathological angiogenesis. Rom J Morphol Embryol 59:455-467

5. Ballmer-Hofer K (2018) Vascular Endothelial Growth Factor, from Basic Research to Clinical Applications. Int. J. Mol. Sci. 2018, 19, 3750; doi:10.3390/ijms19123750

6. Carpini JD, Karam AK, Montgomery L (2010) Vascular endothelial growth factor and its relationship to the prognosis and treatment of breast, ovarian, and cervical cancer. Angiogenesis 13:43-58 
7. Chekhonin VP, Shein SA, Korchagina AA, Gurina OI (2013) VEGF in tumor progression and targeted therapy. Curr Cancer Drug Targets 13:423-443

8. Drevs J (2008) VEGF and angiogenesis: implications for breast cancer therapy. Eur J Cancer Suppl $6: 7-13$

9. Shibuya M (2011) Vascular endothelial growth factor (VEGF) and its receptor (VEGFR) signaling in angiogenesis: a crucial target for anti-and pro-angiogenic therapies. Genes cancer 2:1097-1105

10. Mukherji S (2010) Bevacizumab (avastin). American journal of neuroradiology 31:235-236

11. Shibuya M (2011) Vascular endothelial growth factor (VEGF) and its receptor (VEGFR) signaling in angiogenesis: a crucial target for anti-and pro-angiogenic therapies. Genes cancer 2:1097-1105

12. Deezagi A, Ansari-Majd S, Vaseli-Hagh N (2012) Induced apoptosis in human prostate cancer cells by blocking of vascular endothelial growth factor by siRNA. Clin Transl Oncol 14(10):791-799

13. Koutras AK, Fountzilas G, Makatsoris T, Peroukides S, Kalofonos HP (2010) Bevacizumab in the treatment of breast cancer. Cancer treatment reviews 36:75-82

14. Taugourdeau-Raymond S, Rouby F, Default A, Jean-Pastor M-J, Centers FN o. t. P. 2012. Bevacizumab-induced serious side-effects: a review of the French pharmacovigilance database. European journal of clinical pharmacology, 68, 1103-1107

15. Esmaeili MA. Combination of siRNA-directed gene silencing with epigallocatechin-3-gallate (EGCG) reverses drug resistance in human breast cancer cells. J Chem Biol. 2015;9:41-52. [PMC free article] [PubMed] [Google Scholar]

16. Yang Y, Meng Y, Ye J, Xia X, Wang H, Li L, Dong W, Jin D, Liu Y (2018) Sequential delivery of VEGF siRNA and paclitaxel for PVN destruction, anti-angiogenesis, and tumor cell apoptosis procedurally via a multi-functional polymer micelle. J Controlled Release 287:103-120

17. Chen J, Sun X, Shao R, Xu Y, Gao J, Liang W (2017) VEGF siRNA delivered by polycation liposomeencapsulated calcium phosphate nanoparticles for tumor angiogenesis inhibition in breast cancer. Int J Nanomed 12:6075

18. Eivazy P, Atyabi F, Jadidi-Niaragh F, Maleki A, Miahipour L, Abdolalizadeh A, J. \& Yousefı M (2017) The impact of the codelivery of drug-siRNA by trimethyl chitosan nanoparticles on the efficacy of chemotherapy for metastatic breast cancer cell line (MDA-MB-231). Artificial cells nanomedicine biotechnology 45:889-896

19. Dong $\mathrm{H}$, Yao L, Bi W, et al. Combination of survivin siRNA with neoadjuvant chemotherapy enhances apoptosis and reverses drug resistance in breast cancer MCF-7 cells. J Can Res Ther. 2015;11:717722. [PubMed] [Google Scholar].

20. Tai W, Qin B, Cheng K (2010) Inhibition of breast cancer cell growth and invasiveness by dual silencing of HER-2 and VEGF. Mol Pharm 7:543-556

21. Wang T, Shigdar S, Shamaileh A, Gantier H, Yin MP, Xiang W, Wang D, Zhou L, Hou S-F, Y. \& Wang P (2017) Challenges and opportunities for siRNA-based cancer treatment. Cancer letters 387:77-83 
22. Bobadilla AVP, Arévalo J, Sarró E, Byrne HM, Maini PK, Carraro T, Balocco S, Meseguer A, Alarcón T (2019) In vitro cell migration quantification method for scratch assays. Journal of the Royal Society Interface 16:20180709

23. Tonissi F, Lattanzio L, Merlano MC, Infante L, Nigro CL, Garrone $O$ (2015) The effect of paclitaxel and nab-paclitaxel in combination with anti-angiogenic therapy in breast cancer cell lines. Investig New Drugs 33:801-809

24. Rochlitz C, Ruhstaller T, Lerch S, Spirig C, Huober J, Suter T et.al (2011) Combination of bevacizumab and 2-weekly pegylated liposomal doxorubicin as first-line therapy for locally recurrent or metastatic breast cancer. A multicenter, single-arm phase II trial (SAKK 24/06) Annals of Oncology 22: 80-85, 2011 doi:10.1093/annonc/mdq319

25. Kim MG, Jo SD, Yhee JY, Lee BS, Lee SJ, Park SG, Kang S-W, Kim SH, Jeong JH (2017) Synergistic anti-tumor effects of bevacizumab and tumor targeted polymerized VEGF siRNA nanoparticles. Biochem Biophys Res Commun 489:35-41

26. Ge Y-L, Zhang X, Zhang J-Y, Hou L, Tian R-H (2009)The mechanisms on apoptosis by inhibiting VEGF expression in human breast cancer cells, Int Immunopharmacol, 2009 Apr;9(4):389 - 95. doi: 10.1016/j.intimp.2008.11.020. Epub 2009 Jan 20

27. Chung DC, Le Thanh L, Son HN, Le T Bao, Si DM, Le Van Dong (2015) Downregulation of vascular endothelial growth factor enhances chemosensitivity by induction of apoptosis in hepatocellular carcinoma cells. Cell Journal (Yakhteh) 17(2):273-287

28. Zibara K, Awada Z, Dib L, El-Saghir J, Al-Ghadban S, Ibrik A, El-Zein N, El-Sabban M (2015) Antiangiogenesis therapy and gap junction inhibition reduce MDA-MB-231 breast cancer cell invasion and metastasis in vitro and in vivo. Scientific reports 5:1-16

\section{Figures}



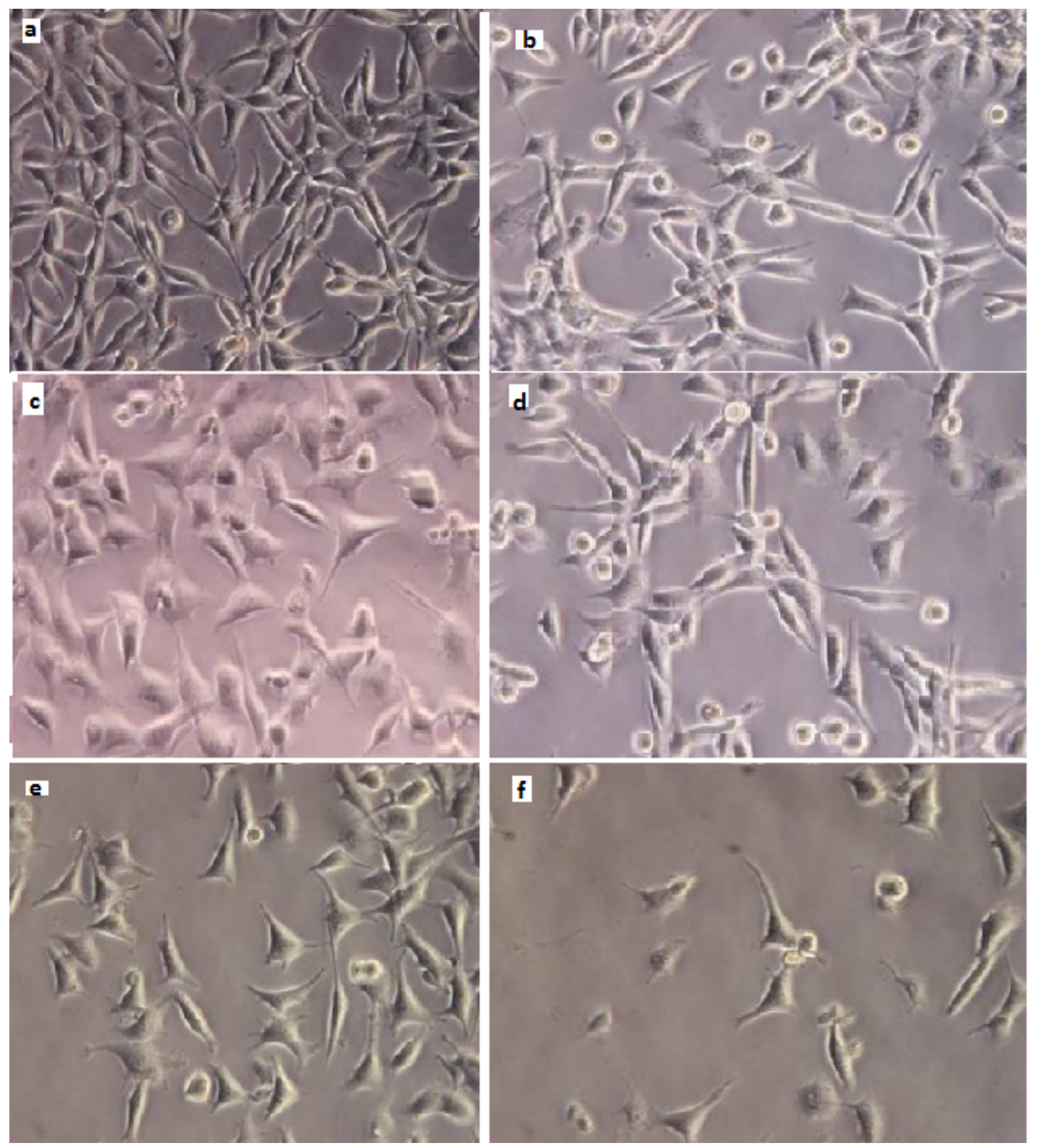

\section{Figure 1}

The effects of Avastin and VEGF siRNA on the morphology, cell proliferation and growth of MCF-7 cells. The cells were treated by Avastin and/or VEGF siRNA and incubated $72 \mathrm{hr}$ and images were photographed by microscope. a: Untreated control cells after $72 \mathrm{hr}$ incubation. b, c and d: The cells treated by 25,50 and $100 \mu \mathrm{g} / \mathrm{ml}$ of Avastin respectively. The cells density and proliferation were slightly suppressed by Avastin. e: The cells treated by VEGF siRNA. The cells density and proliferation were moderately suppressed. $\mathrm{f}$ : The cells treated by combination of $100 \mu \mathrm{g} / \mathrm{ml}$ of Avastin and VEGF siRNA. The cells density and proliferation were strongly suppressed. (Magnification: $\times 400$ ) 

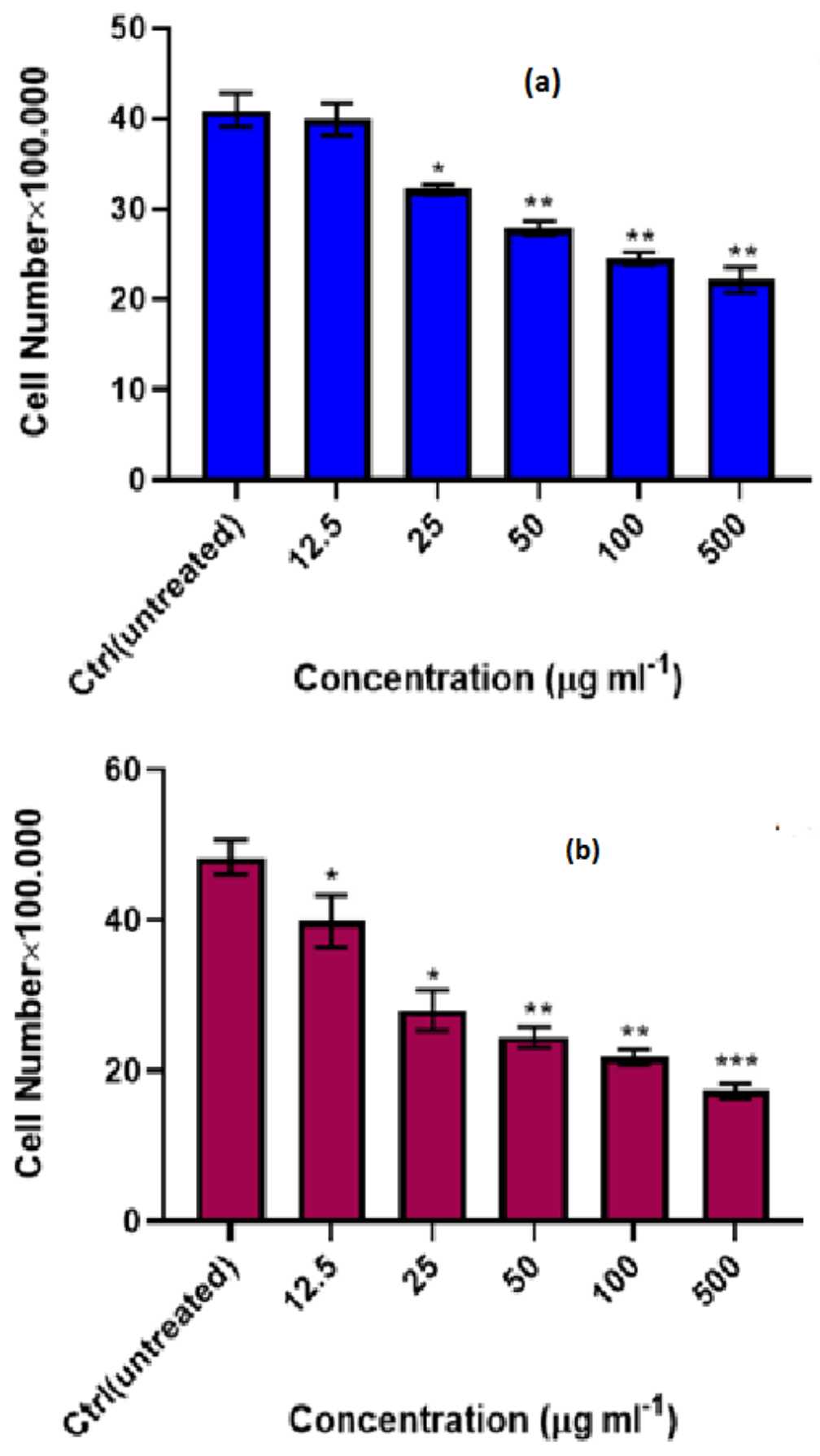
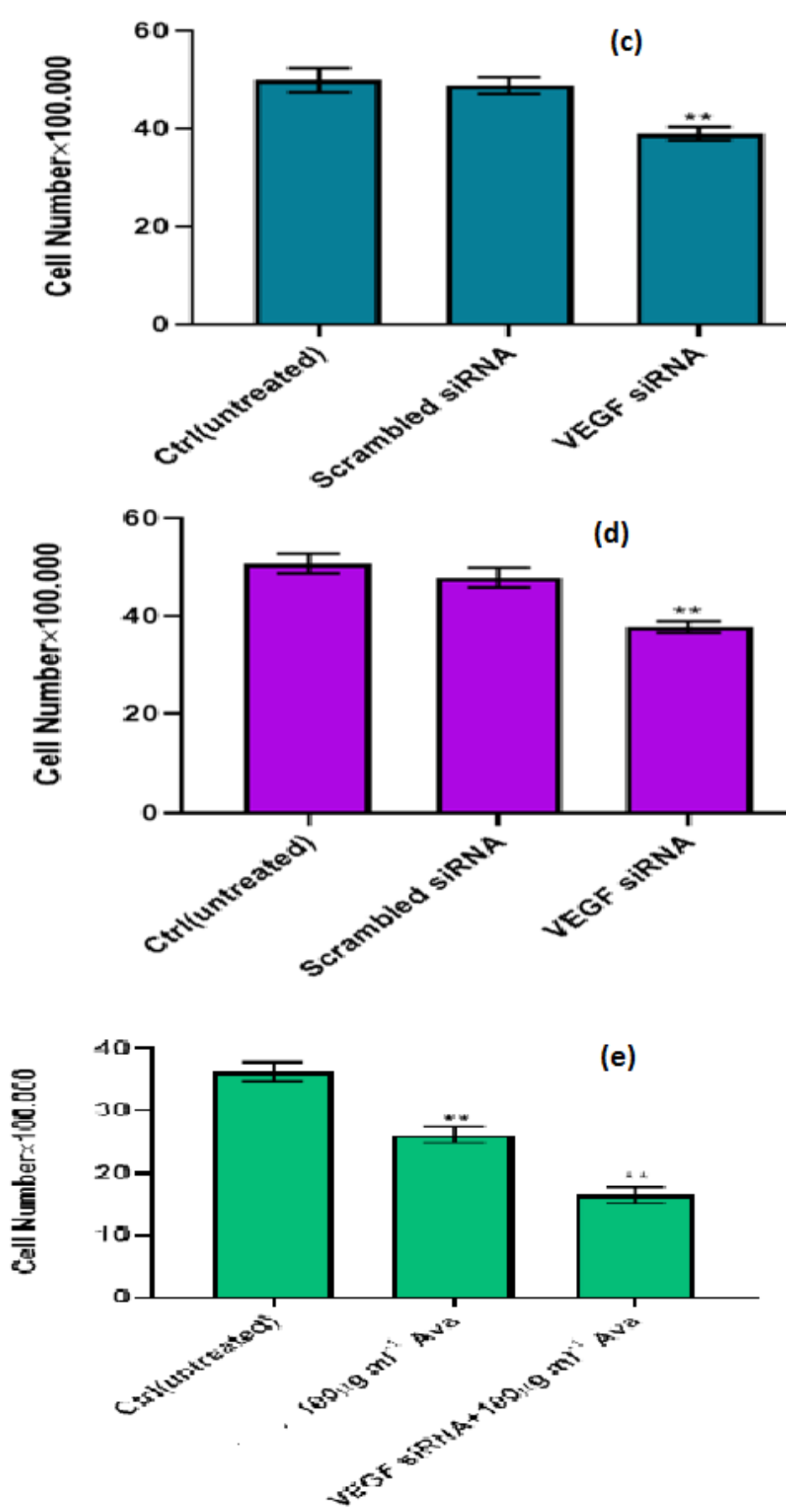

Figure 2

The effect of Avastin and VEGF siRNA on the cell growth and proliferation according cell count. For cell proliferation assay, the control and treated cells were collected after treatment and $48-72$ hrs incubation. Total cell number was determined using a hemo-cytometer. Cell count after treatment by Avastin for 48 (a) , $72 \mathrm{hr}(\mathrm{b})$, VEGF siRNA $48 \mathrm{hr}(\mathrm{c})$ and $72 \mathrm{hr}$ (d). e indicate treatment of cells in combination for $48 \mathrm{hr}$. (* $p<0.1, \star \star p<0.05$ and $\star \star \star x<0.01)$. All experiments were repeated 3 times in duplicates. The results are mean \pm 1.0 SD for three separate experiments. 

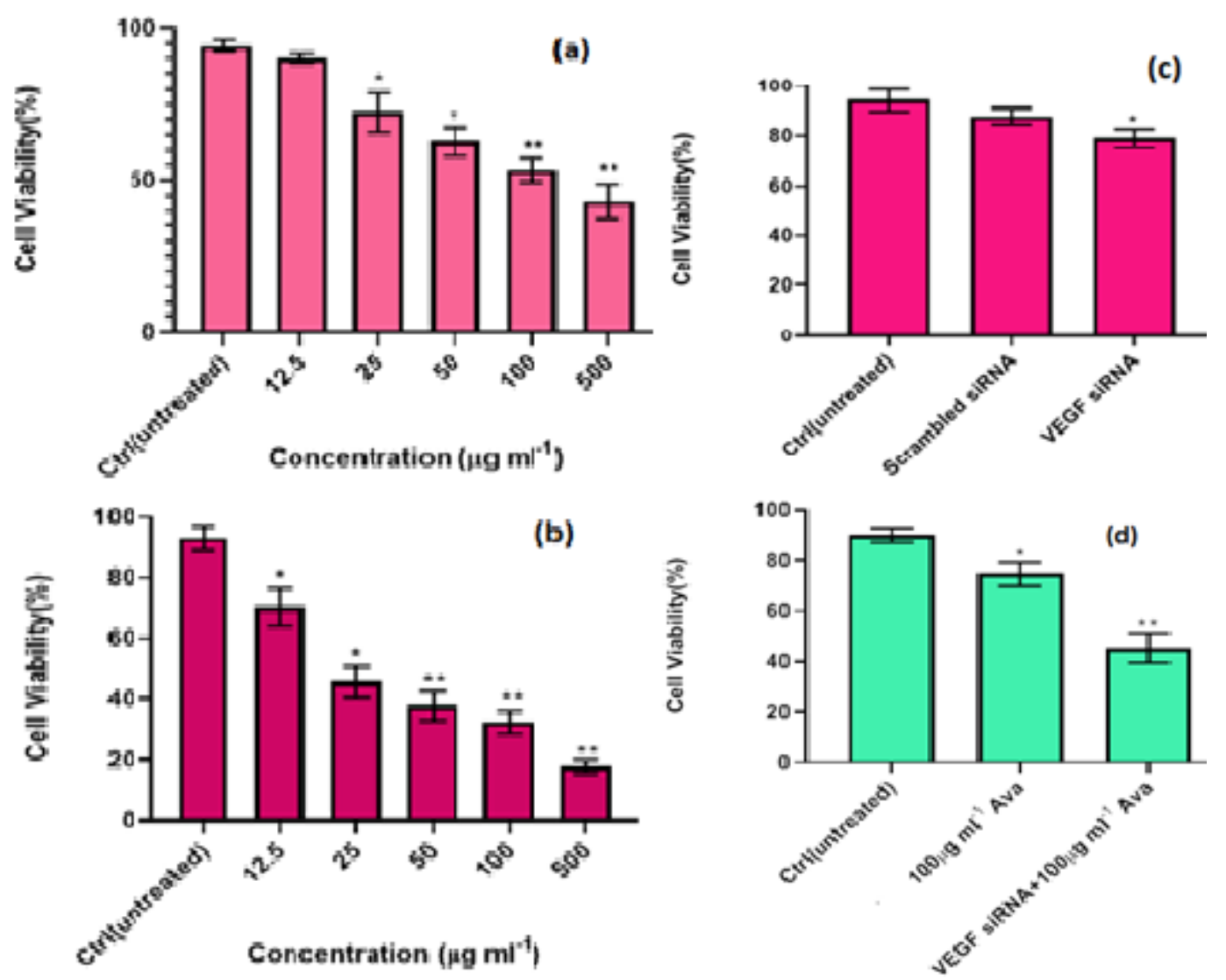

\section{Figure 3}

The effect of Avastin and VEGF siRNA on the cell viability by trypan blue test. For viability assay, the control and treated cells were collected after treatment and 48 - 72 hrs incubation and trypan blue dye exclusion by viable cells was determined and counted using a hemo-cytometer. \% of viable cells after treatment by Avastin for 48 (a) , $72 \mathrm{hr}(\mathrm{b})$, VEGF siRNA $72 \mathrm{hr}$ (c) and combination treatment for $72 \mathrm{hr}(\mathrm{d})$. $\left({ }^{\star} p<.0 .05,{ }^{* \star} p<0.01\right)$. All experiments were repeated 3 times in duplicates. The results are mean $\pm 1.0 \mathrm{SD}$ for three separate experiments 

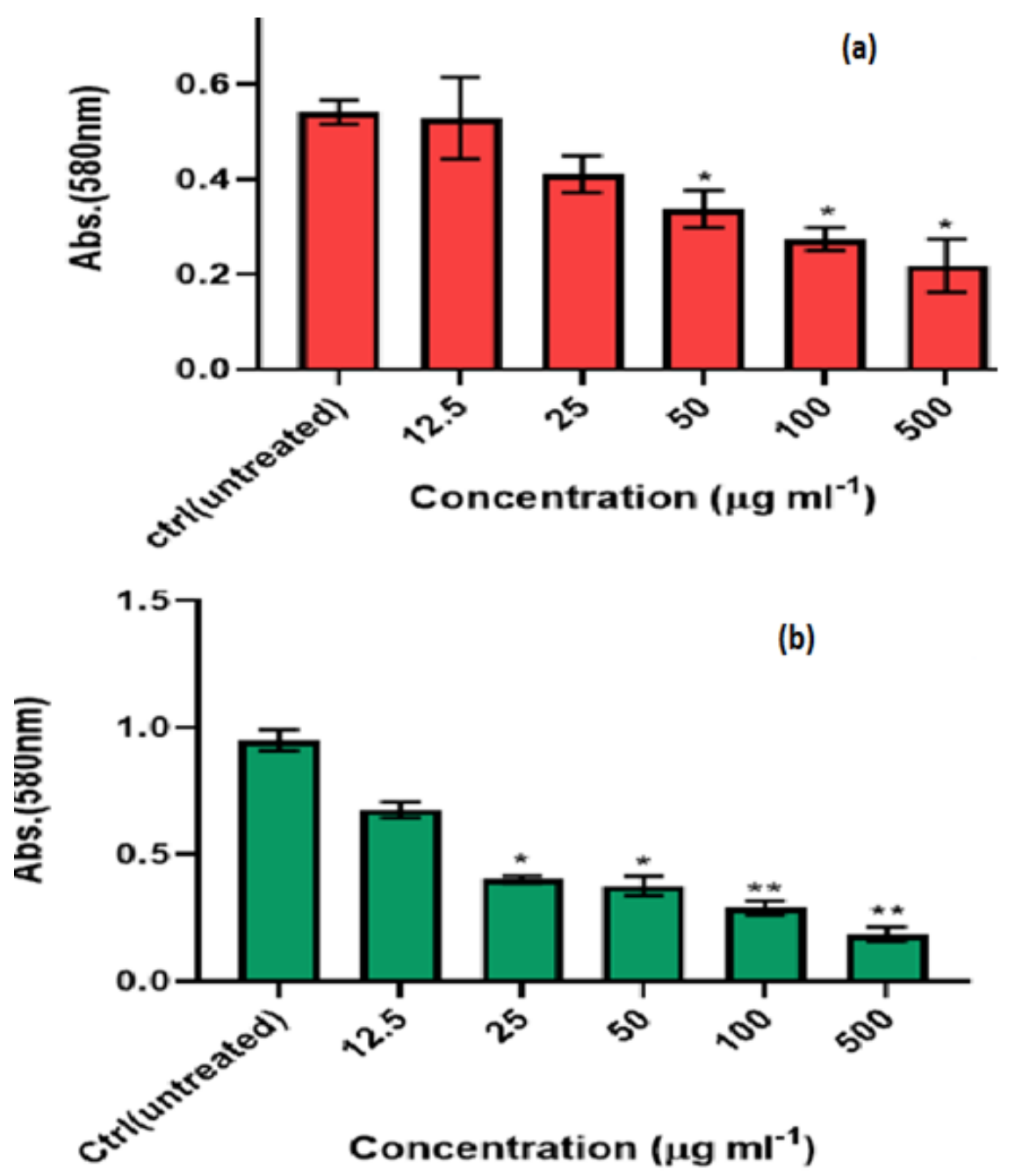

(c)

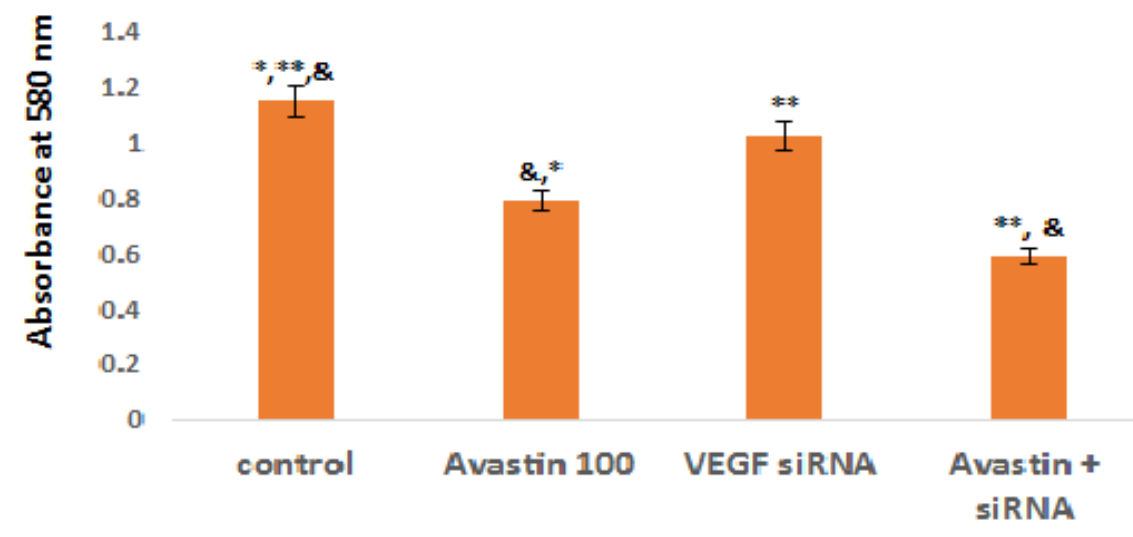

Figure 4

The effect of Avastin and VEGF siRNA on the cell growth and proliferation according MTT assay. The control and treated cells were assayed by MTT after treatment and 48 - $72 \mathrm{hrs}$ incubation as described in materials and methods. Measured absorbance at $580 \mathrm{~nm}$ after treatment by Avastin for 48 (a) , $72 \mathrm{hr}(\mathrm{b})$, VEGF siRNA and combination after $72 \mathrm{hr}(\mathrm{c}) .$. (* $p<0.05,{ }^{\star \star} \mathrm{p}<0.01$ and $\left.\& \mathrm{p}<0.005\right)$. All experiments were repeated 3 times in duplicates. The results are mean \pm 1.0 SD for three separate experiments. 

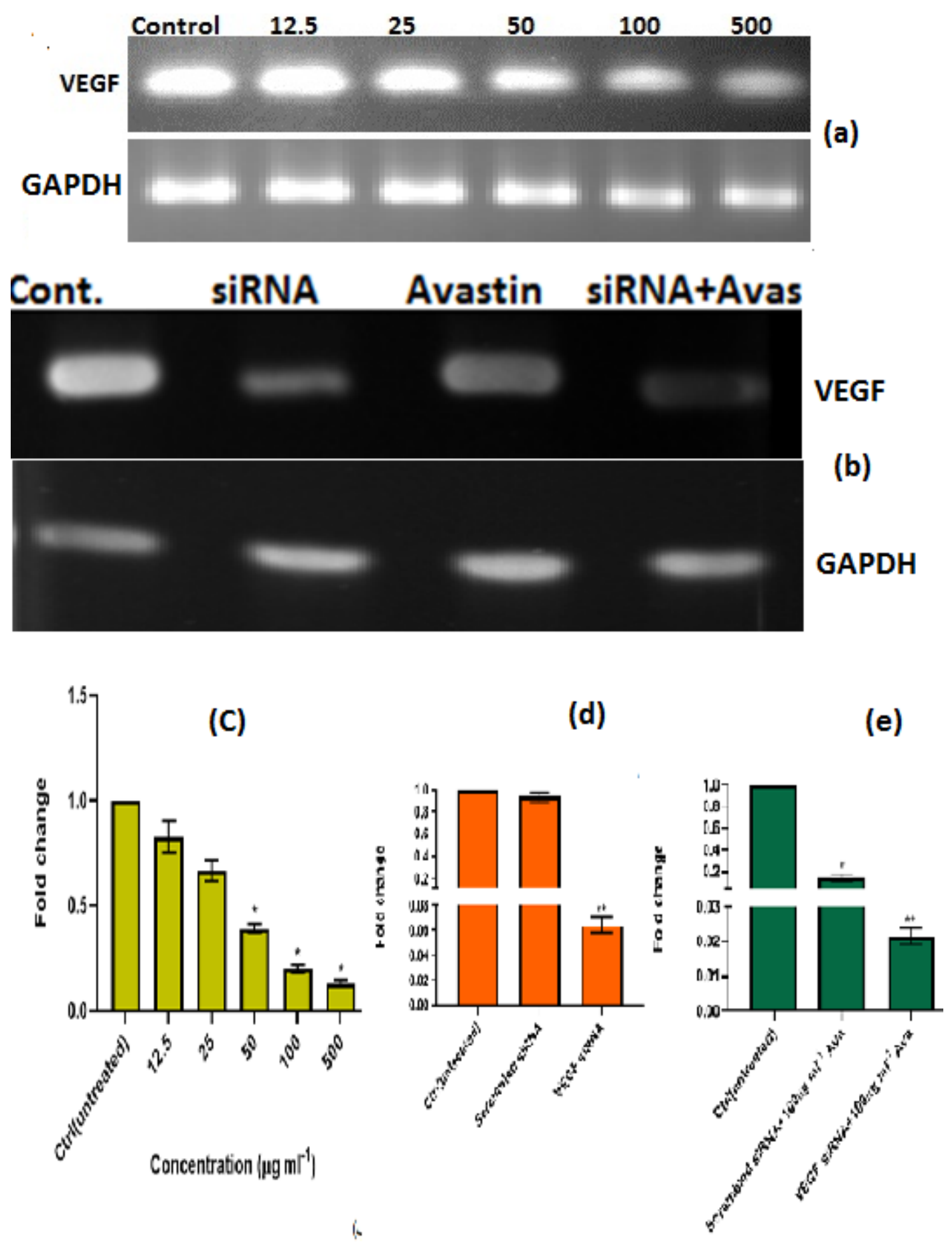

Figure 5

Changes in VEGF genes expression during treatment of MCF-7 cells by Avastin and/or VEGF siRNA. MCF7 cells were incubated with Avastin (up to $100 \mu \mathrm{g} / \mathrm{ml}$ ) and/or VEGF siRNA for $72 \mathrm{~h}$ as described in "Materials and Methods". Then, total RNA was extracted from untreated and treated cells and amplified by RT-PCR for gene expression. a) The agarose gel electrophoresis pattern of PCR products from Avastin treated cells. b) The agarose gel electrophoresis pattern of PCR products from VEGF siRNA and combination of them by $100 \mu \mathrm{g} / \mathrm{ml}$ of Avastin. Total RNA was extracted from untreated and treated cells and amplified by Real-Time RT-PCR for gene expression too. The Real Time PCR results were quantified and normalized against untreated control cells and GAPDH as an internal housekeeping gene control. C, 
$\mathrm{d}$ and e indicate for response to Avastin, VEGF siRNA and combination of them respectively. * indicated 50 and $100 \mu \mathrm{g} / \mathrm{ml}$ of Avastin in comparison to untreated control cells $(p<0.01$. ** indicated VEGF siRNA and combination of them by Avastin in comparison to untreated control cells $(p<0.001)$. All experiments were repeated 3 times in duplicates. The results are mean \pm 1.0 SD for three separate experiments.

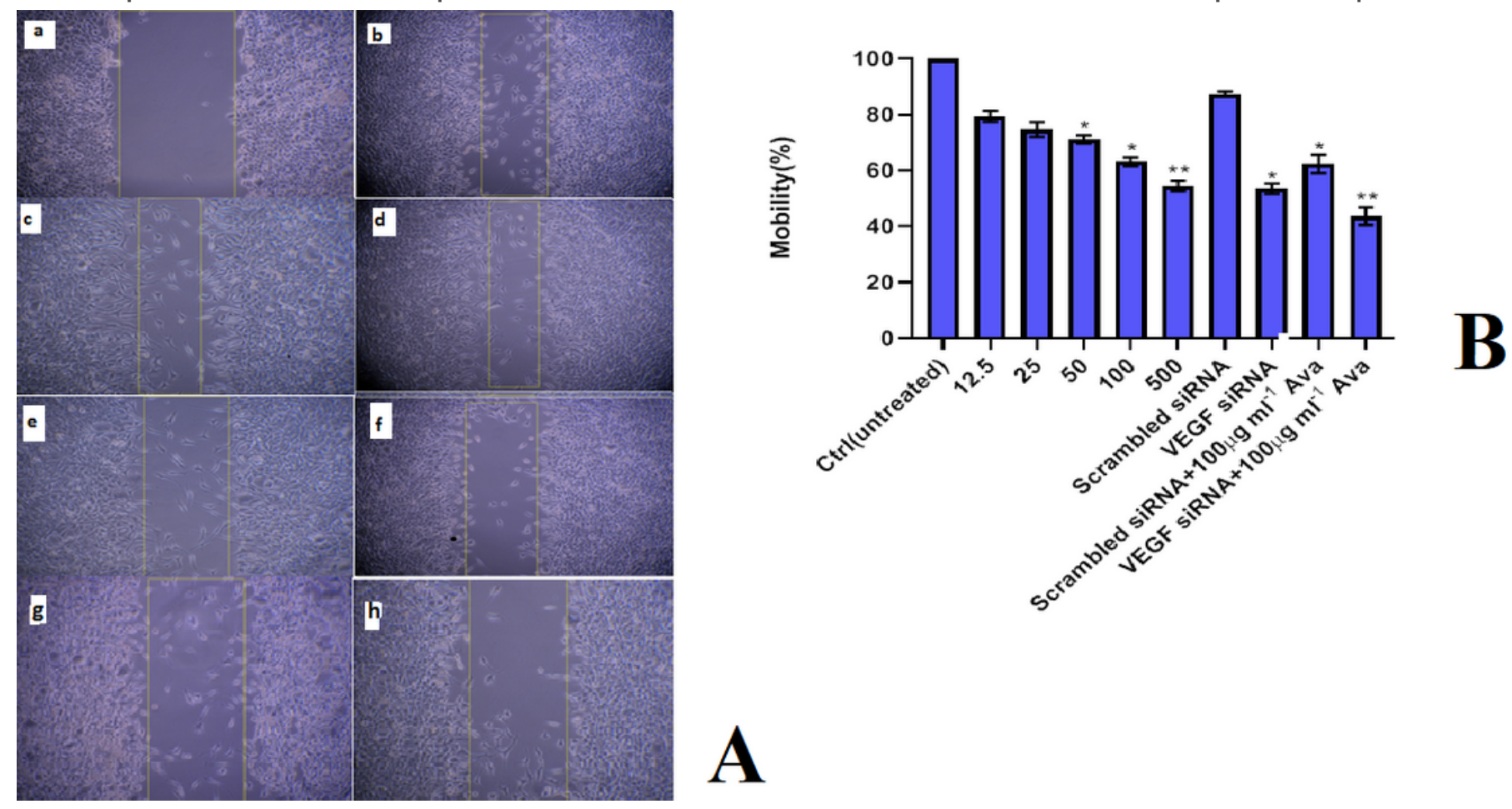

\section{Figure 6}

The effects of Avastin and/or VEGF siRNA and their combination on the growth, proliferation, migration and healing of MCF-7 cells according scratching wound healing assay after $72 \mathrm{hr}$ as described in materials and methods. The MCF-7 cells were grown in RPMI medium in the absence or presence of those agent. The cells were assessed for migration by the scratching method. The distance of migration and relative surface coverage area were calculated by the program which is described in methods. A) The morphology and photographs of the cells at $72 \mathrm{hr}$. a) The scratched region at time zero, b) Untreated control cells, c , d , e and $\mathrm{f}$ the cells treated by $12.5,25,50$ and $100 \mu \mathrm{g} / \mathrm{ml}$ of Avastin respectively. $\mathrm{g}$ and $\mathrm{h}$ indicate for VEGF siRNA and its combination by $100 \mu \mathrm{g} / \mathrm{ml}$ of Avastin respectively (magnification: × 100).

B) The distance of migration and relative surface coverage area were calculated and quantified by the program which is described in methods., * indicate $50-500 \mu \mathrm{g} / \mathrm{ml}$ of Avastin in comparison to untreated cells and alone treatment $\mathrm{ml}$ of Avastin $(*, \mathrm{p}<0.05)$. ** indicate VEGF siRNa and its combination by 100 $\mu \mathrm{g} / \mathrm{ml}$ of Avastin in comparison to untreated cells and alone treatment $(*, p<0.01)$. All experiments were repeated 3 times in duplicates. The results are mean \pm 1.0 SD for three separate experiments.

\section{Supplementary Files}

This is a list of supplementary files associated with this preprint. Click to download. 
- Highlights.docx

Page 19/19 